\title{
INFLUÊNCIA DA TEMPERATURA NAS PROPRIEDADES FÍSICAS E MECÂNICAS DE CERÂMICA PRODUZIDA COM ADIÇÃO DE CHAMOTE *
}

Verônica Silva Costa Medeiros ${ }^{1}$ Heraldo Nunes Pitanga ${ }^{2}$ Leonardo Gonçalves Pedroti ${ }^{3}$ Beatryz Cardoso Mendes ${ }^{4}$ José Carlos Borba Júnior Márcia Maria Salgado Lopes ${ }^{6}$

\begin{abstract}
Resumo
O chamote é um resíduo proveniente da indústria cerâmica, classificado como material não-plástico. Tal rejeito pode ser retornado ao processo de produção de cerâmicas, substituindo parte da matéria-prima convencional. O objetivo deste trabalho foi avaliar a incorporação de chamote nas propriedades físicas e mecânicas de peças cerâmicas sob três temperaturas de queima distintas: $850^{\circ} \mathrm{C}, 950^{\circ} \mathrm{C} \mathrm{e}$ $1050^{\circ} \mathrm{C}$. As matérias-primas utilizadas na pesquisa foram caracterizadas quanto à granulometria, limites de consistência e composição química por meio de EDX. Foram propostas três misturas, contendo 0\%, 13,33\% e 40\% do resíduo. Corpos de prova prismáticos foram produzidos por prensagem e, após, realizou-se os ensaios de determinação da retração na queima, índice de absorção de água e resistência à flexão. Os resultados revelam que, quanto maior a temperatura, maior a retração linear na queima e a resistência à flexão em todas as misturas. Em relação à absorção, foram observados menores valores a $1050^{\circ} \mathrm{C}$, devido ao processo de vitrificação. Verificou-se que a adição de chamote reduz a retração; no entanto, reduz também a resistência mecânica. Dentre as misturas com resíduo, a composição com 13,33\% apresentou melhores resultados, sobretudo sob a temperatura de $1050^{\circ} \mathrm{C}$.
\end{abstract}

Palavras-chave: Chamote; Cerâmica; Propriedades; Temperatura.

\section{INFLUENCE OF TEMPERATURE IN THE PHYSICAL AND MECHANICAL PROPERTIES OF CERAMICS PRODUCED WITH GROG}

\section{Abstract}

Grog is a residue from the ceramic industry, classified as non-plastic material. This waste can be returned to the process of producing ceramics, replacing part of the conventional raw material. The objective of this work was to evaluate the incorporation of grog in the physical and mechanical properties of ceramic bricks under three different firing temperatures: $850^{\circ} \mathrm{C}, 950^{\circ} \mathrm{C}$ and $1050^{\circ} \mathrm{C}$. The raw materials used in the research were characterized as granulometry, limits of consistency and chemical composition by means of EDX. Three mixtures containing $0 \%, 13.33 \%$ and $40 \%$ of the residue were proposed. Prismatic specimens pressed were produced and determination of shrinkage, water absorption and flexural strength tests were realized. The results show that the higher the temperature, the greater the linear shrinkage and the flexural strength in all the mixtures. Regarding the absorption, lower values were observed at $1050^{\circ} \mathrm{C}$ due to the vitrification process. It was observed that addition of grog reduces shrinkage; however, it also reduces mechanical strength. Among the mixtures with residue, the composition with $13.33 \%$ showed better results, especially under the temperature of $1050^{\circ} \mathrm{C}$. 
Keywords: Grog; Ceramic; Properties; Temperature.

1 Arquiteta, graduada, mestranda, Departamento de Engenharia Civil, Universidade Federal de São João Del Rei, São João Del Rei, Minas Gerais, Brasil.

2 Engenheiro Civil, doutor, professor orientador, Departamento de Engenharia Civil, Instituição de trabalho elou estudo, cidade, Minas Gerais, Brasil.

3 Engenheiro Civil, doutor, professor, Departamento de Engenharia Civil, Universidade Federal de Viçosa, Viçosa, Minas Gerais, Brasil.

4 Engenheira Civil, graduada, mestranda, Departamento de Engenharia Civil, Universidade Federal de Viçosa, Viçosa, Minas Gerais, Brasil.

5 Engenheiro Civil, mestre, doutorando, Departamento de Engenharia Civil, Universidade Federal de Viçosa, Viçosa, Minas Gerais, Brasil.

6 Engenheira Civil, graduada, mestranda, Departamento de Engenharia Civil, Universidade Federal de Viçosa, Viçosa, Minas Gerais, Brasil. 


\section{INTRODUÇÃO}

Peças defeituosas resultantes da etapa de queima da cerâmica vermelha constituem um resíduo cerâmico conhecido como chamote [1]. Segundo levantamento feito por Sales e Filho [2], o percentual de perdas no processo produtivo da cerâmica varia entre indústrias da região Sudeste; mas, no geral, apresenta valores em torno de $0,5 \%$ até $15 \%$.

Alternativas de reaproveitamento deste resíduo em materiais de construção civil, como aglomerantes, argamassa e concreto, foram estudadas por Gomes et al. [3], Paixão [4] e Amorin et al. [5]. Os trabalhos desenvolvidos por Zaccaron et al. [6] e Gouveia e Sposto [7] mostraram a viabilidade de retornar tal rejeito ao processo de produção de peças cerâmicas, substituindo parte da matéria-prima convencional - a argila.

O chamote é caracterizado como material não-plástico que, quando adicionado nas massas para a fabricação dos produtos da cerâmica vermelha, altera 0 comportamento das mesmas durante o processamento e as características do produto final [8]. Para o aproveitamento do chamote com maior eficácia é necessário que este seja queimado uma segunda vez, acima da sua temperatura de processamento inicial. As reações e transformações de sinterização que irão ocorrer vão contribuir para a diminuição do efeito negativo sobre a resistência mecânica das peças finais $[1,9]$.

O objetivo do presente trabalho foi a avaliação da incorporação de chamote, em duas diferentes proporções, nas propriedades físicas e mecânicas de peças cerâmicas sob três diferentes temperaturas de queima: $850^{\circ} \mathrm{C}, 950^{\circ} \mathrm{C}$ e $1050^{\circ} \mathrm{C}$. Foram adotadas as porcentagens de $0,13,33 \%$ e $40 \%$ do rejeito, de modo a manter a mesma proporção entre a quantidade de argilas. Até então, o teor máximo comumente estudado foi de $20 \%$ de adição do resíduo $[1,6,7]$.

Este estudo mostra-se relevante, uma vez que o reaproveitamento de resíduos, além de diminuir os impactos ambientais causados pela sua disposição incorreta no ambiente, gera também a economia de matérias-primas. Configura-se, então, uma boa alternativa para as indústrias, tornando o processo produtivo mais sustentável sem comprometer a qualidade dos produtos finais.

\section{MATERIAIS E MÉTODOS}

Amostras das matérias-primas utilizadas na produção dos corpos de prova cerâmicos foram coletadas em uma indústria localizada no município de Conselheiro Lafaiete, MG, e levadas ao Laboratório de Materiais de Construção da Universidade Federal de Viçosa (UFV).

Foram empregados dois tipos de argila - argila amarela e argila preta - e o resíduo de blocos cerâmicos, mostrados na Figura 1. As argilas foram caracterizadas quanto à granulometria [10], massa específica dos sólidos [11], limites de consistência [12] e composição química, através da técnica de espectrometria de raios X (EDX). 


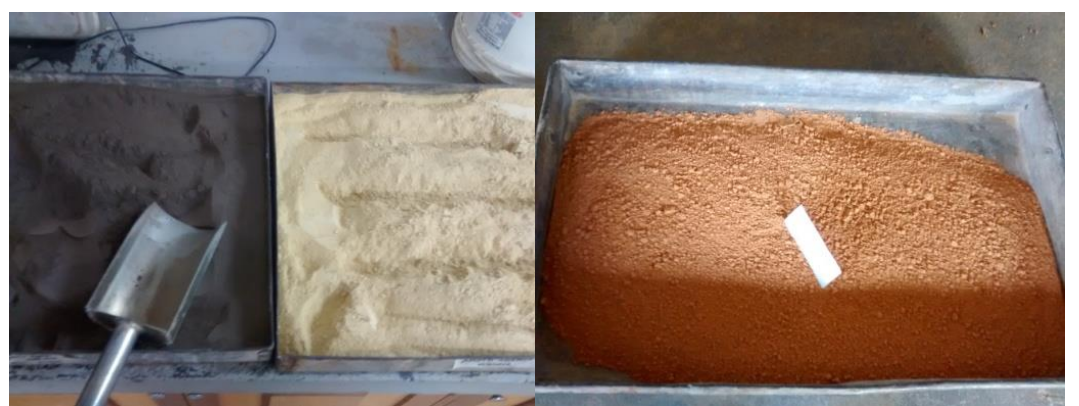

Figura 1. Argila preta, argila amarela e resíduo de bloco cerâmico, respectivamente.

A seguir, foram realizadas três diferentes misturas: a primeira $(A)$, contendo $50 \%$ de argila preta e $50 \%$ de argila amarela; a segunda (B) composta por $30 \%$ de argila preta, $30 \%$ de argila amarela e $40 \%$ de chamote; e a terceira (C), com $43,33 \%$ de argila preta, $43,33 \%$ de argila amarela e $13,33 \%$ de chamote.

A partir destas misturas, foram preparados quinze corpos de prova prismáticos para cada uma. Estes foram obtidos por prensagem (Figura 2), estando as misturas na umidade padrão adotada de $8 \%$. Então, foram avaliados quanto à retração na secagem.

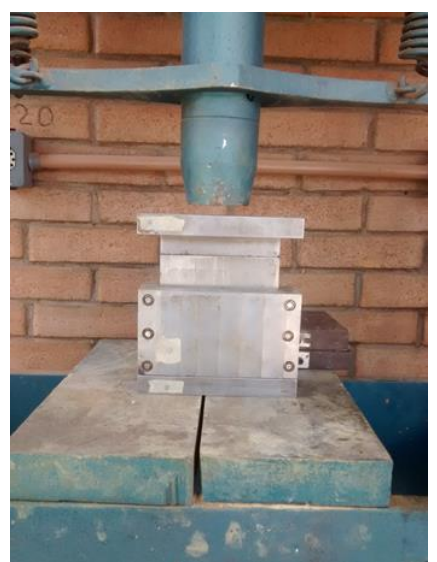

Figura 2. Prensagem dos corpos de prova prismáticos.

$\mathrm{Na}$ sequência, os exemplares foram submetidos à queima em três temperaturas distintas: $850^{\circ} \mathrm{C}, 950^{\circ} \mathrm{C}$ e $1050^{\circ} \mathrm{C}$. Foram sinterizados cinco corpos de prova de cada mistura em cada uma destas temperaturas. Observa-se, na Figura 3, o estado pré e pós queima dos mesmos.
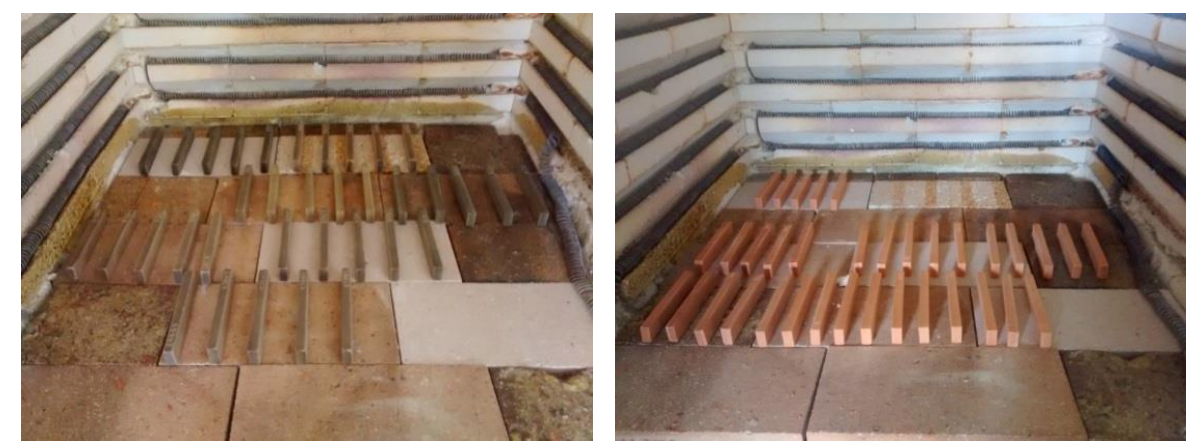

Figura 3. Estado pré e pós queima dos exemplares, respectivamente.

Após esta etapa, as unidades experimentas foram avaliados quanto à retração na queima, índice de absorção de água e resistência à flexão. 
A retração na queima é representada pela variação linear entre o corpo de prova seco e queimado, calculada através da Equação 1.

$$
V L_{\text {calc }}=\frac{L_{2}-L_{3}}{L_{3}} \times 100
$$

onde:

$V L_{\text {calc }}$ - Variação linear entre o corpo de prova seco e queimado (\%);

$L_{2}$ - Comprimento do corpo de prova após a secagem em estufa, a $110^{\circ} \mathrm{C}$;

$L_{3}$ - Comprimento do corpo de prova após a queima.

A determinação do índice de absorção de água (Figura 4) se deu após a imersão dos exemplares, previamente secos em estufa, em um recipiente com água durante 24 horas. O índice de absorção foi calculado a partir dos dados de massa seca e úmida, e expresso em porcentagem (\%).

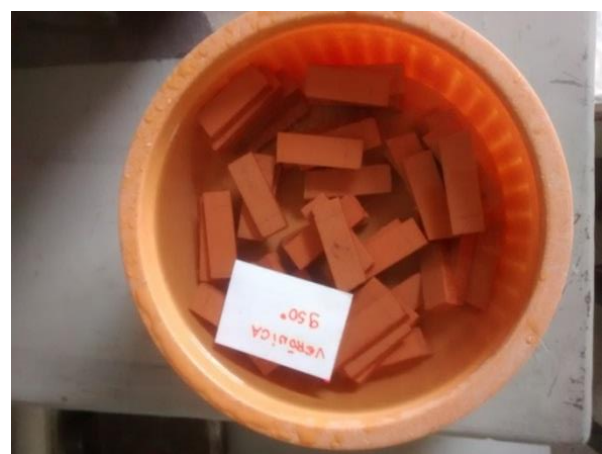

Figura 4. Ensaio de determinação do índice de absorção.

A resistência à flexão foi obtida através do ensaio de tensão de ruptura à flexão, que consiste na aplicação de uma carga concentrada no centro do vão do corpo de prova biapoiado, como observa-se na Figura 5. A técnica utilizada é chamada de carregamento em três pontos.

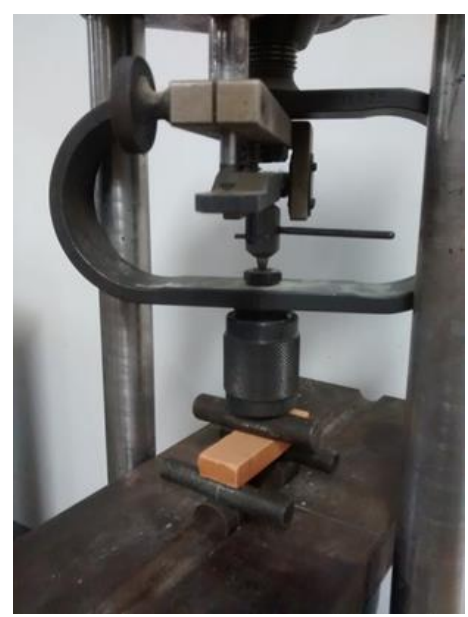

Figura 5. Ensaio de determinação da resistência à flexão.

\section{RESULTADOS E DISCUSSÃO}

Os resultados de granulometria para as argilas preta e amarela estão apresentados a seguir, nas Figuras 6 e 7 e Tabelas 1 e 2, respectivamente. 


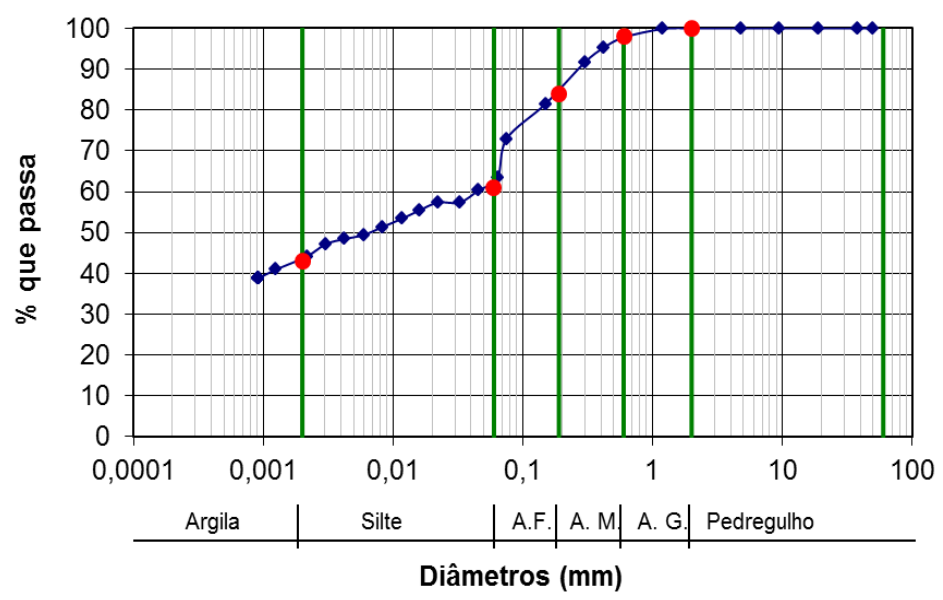

Figura 6. Curva granulométrica da argila preta.

Tabela 1. Classificação granulométrica da argila preta segundo a ABNT NBR 7181 [10].

Argila

$43 \%$
Silte

$18 \%$
Areia $39 \%$
Pedregulho $0 \%$

Pela composição obtida, observa-se que a argila preta é um material argilo-arenosiltoso. Sua fração granulométrica dominante é de argila, seguido pela elevada fração de areia. Partículas de areia podem acarretar problemas na etapa de queima se estiverem quando em elevada quantidade, gerando trincas causadas pela transformação alotrópica do quartzo e, consequentemente, redução na resistência mecânica. Por outro lado, a presença de areia em quantidades moderadas controla a retração por secagem e queima e aumenta a resistência mecânica.

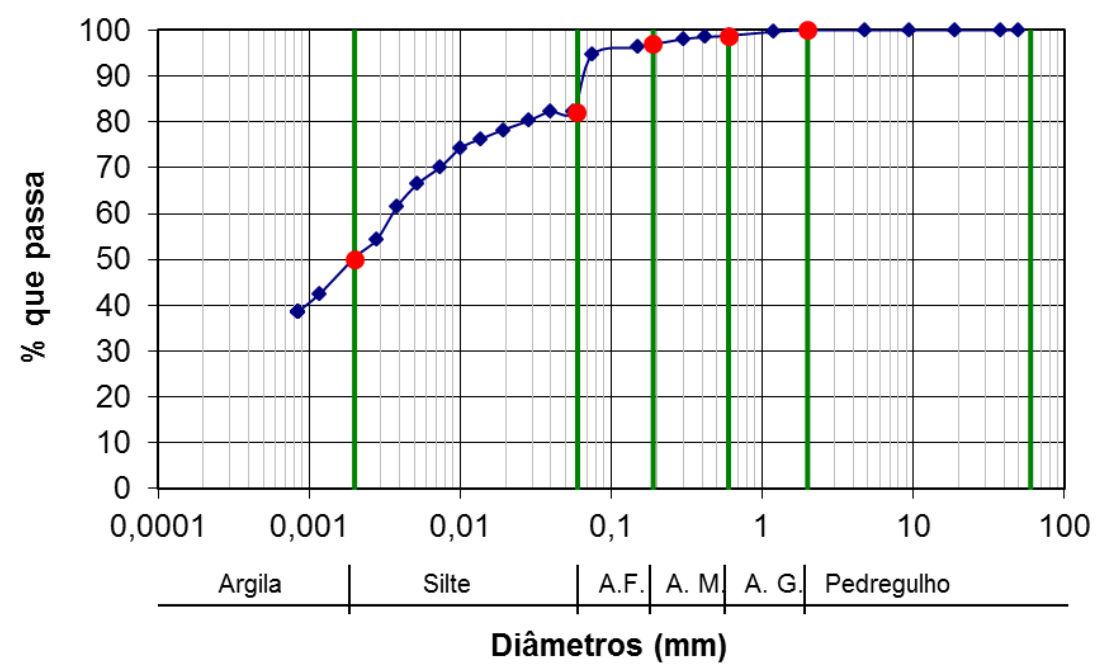

Figura 7. Curva granulométrica da argila amarela.

Tabela 2. Classificação granulométrica da argila preta segundo a ABNT NBR 7181 [10].

\begin{tabular}{cccc}
\hline Argila & Silte & Areia & Pedregulho \\
\hline $50 \%$ & $32 \%$ & $18 \%$ & $0 \%$ \\
\hline
\end{tabular}

Já a argila amarela trata-se de material argilo-silto-arenoso. A maior fração granulométrica encontrada foi a de argila, o que vem a ser um fator importante para a produção de produtos cerâmicos uma vez que esta garante maior plasticidade à mistura. 
Os limites de Atterberg encontrados para os dois materiais supracitados constam nas Tabelas 3 e 4.

Tabela 3. Limites de Atterberg para a argila preta.

\begin{tabular}{cc}
\hline Limite & Valor \\
\hline Limite de Liquidez (\%) & 37 \\
\hline Limite de Plasticidade (\%) & 23 \\
\hline Índice de Plasticidade (\%) & 14 \\
\hline
\end{tabular}

Tabela 4. Limites de Atterberg para a argila amarela.

\begin{tabular}{cc}
\hline Limite & Valor \\
\hline Limite de Liquidez (\%) & 54 \\
\hline Limite de Plasticidade (\%) & 30 \\
\hline Índice de Plasticidade (\%) & 24 \\
\hline
\end{tabular}

De acordo com a classificação dada por [13], a argila preta apresenta plasticidade média. A argila amarela pode ser considerada como muito plástica, o que já era esperado devido à maior fração de argila existente.

Os resultados obtidos para o resíduo confirmaram que o mesmo se trata de material não plástico.

$\mathrm{Na}$ Tabela 5 são apresentadas as composições químicas das duas argilas utilizadas no trabalho.

Tabela 5. Composições químicas das argilas obtidas por EDX.

\begin{tabular}{ccccccccc}
\hline \multirow{2}{*}{ Material } & $\mathrm{SiO}_{2}$ & $\mathrm{Al}_{2} \mathrm{O}_{3}$ & $\mathrm{Fe}_{2} \mathrm{O}_{3}$ & $\mathrm{MgO}$ & $\mathrm{K}_{2} \mathrm{O}$ & $\mathrm{Na}_{2} \mathrm{O}$ & $\mathrm{TiO}_{2}$ & $\mathrm{CO}_{3}$ \\
\hline $\begin{array}{c}\text { Argila } \\
\text { Preta }\end{array}$ & 40,97 & 21,10 & 11,47 & 1,41 & 0,00 & 2,02 & 1,74 & 19,54 \\
\hline $\begin{array}{c}\text { Argila } \\
\text { amarela }\end{array}$ & 38,50 & 23,15 & 5,73 & 1,27 & 1,64 & 1,27 & 0,00 & 26,72 \\
\hline
\end{tabular}

Nas argilas analisadas, tem-se que o elemento $\mathrm{SiO}_{2}$ é encontrado em altas porcentagens nas duas amostras. Esse composto está relacionado à resistência mecânica da peça cerâmica, à redução da plasticidade da argila e com o controle de retração na queima, propriedades importantes para produção de peças cerâmicas [14].

O elemento $\mathrm{CO}_{3}$ varia de $19,54 \%$ a $26,72 \%$ nas argilas preta e amarela, respectivamente. A presença do óxido relaciona-se à presença de matéria orgânica, que pode gerar aumento dos poros na peça final. Durante o processo de queima, esta matéria orgânica é eliminada, dando origem a poros que podem influenciar na resistência mecânica e absorção de água [15].

Analisando os resultados de variação linear (ou retração) nos corpos de prova das três misturas feitas ( $\mathrm{A}, \mathrm{B}$ e $\mathrm{C}$ ), obteve-se o gráfico apresentado na Figura 8. 


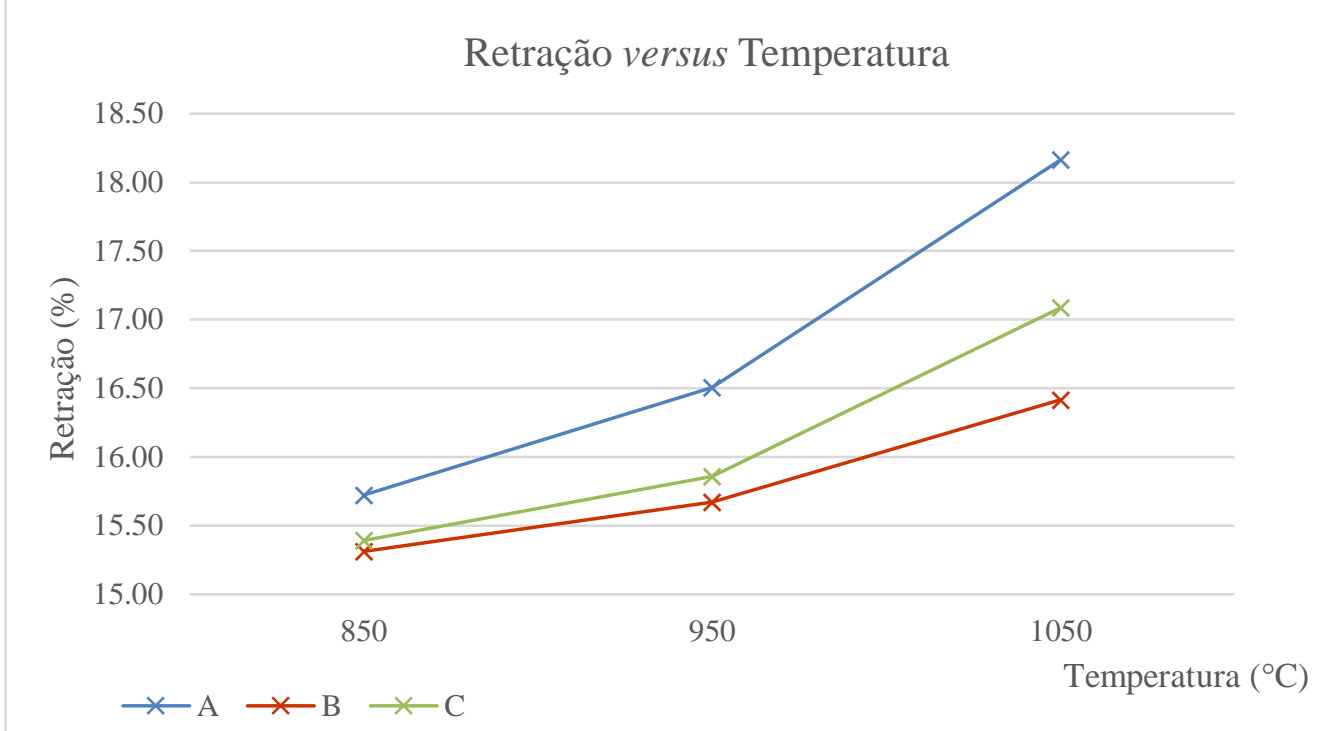

Figura 8. Curvas de Retração versus temperatura para as três misturas propostas: A, B e C.

De acordo com o gráfico acima, pode-se observar um aumento na variação linear proporcional ao aumento da temperatura. Isto ocorre devido a uma maior densificação do material e consequente diminuição da porosidade. Ressalta-se também que a $1050^{\circ} \mathrm{C}$ o aumento da retração é mais significativo para todas as composições. Com isso, o risco de trincas de aquecimento é maior.

Com relação às misturas, os menores valores de variação são vistos na mistura $B$, que contem $40 \%$ de resíduo, seguida da mistura C (13,33\% de resíduo). Portanto, é evidente que a adição do chamote diminui a retração na queima, o que também foi observado por Pracidelli e Melchiades [8] e Campelo et al. [9]. Esse comportamento é satisfatório em blocos cerâmicos, uma vez que possibilita a diminuição da ocorrência de trincas por retração nas unidades.

Em relação aos índices de absorção dos corpos de prova avaliados, os resultados obtidos estão expressos no gráfico da Figura 9.

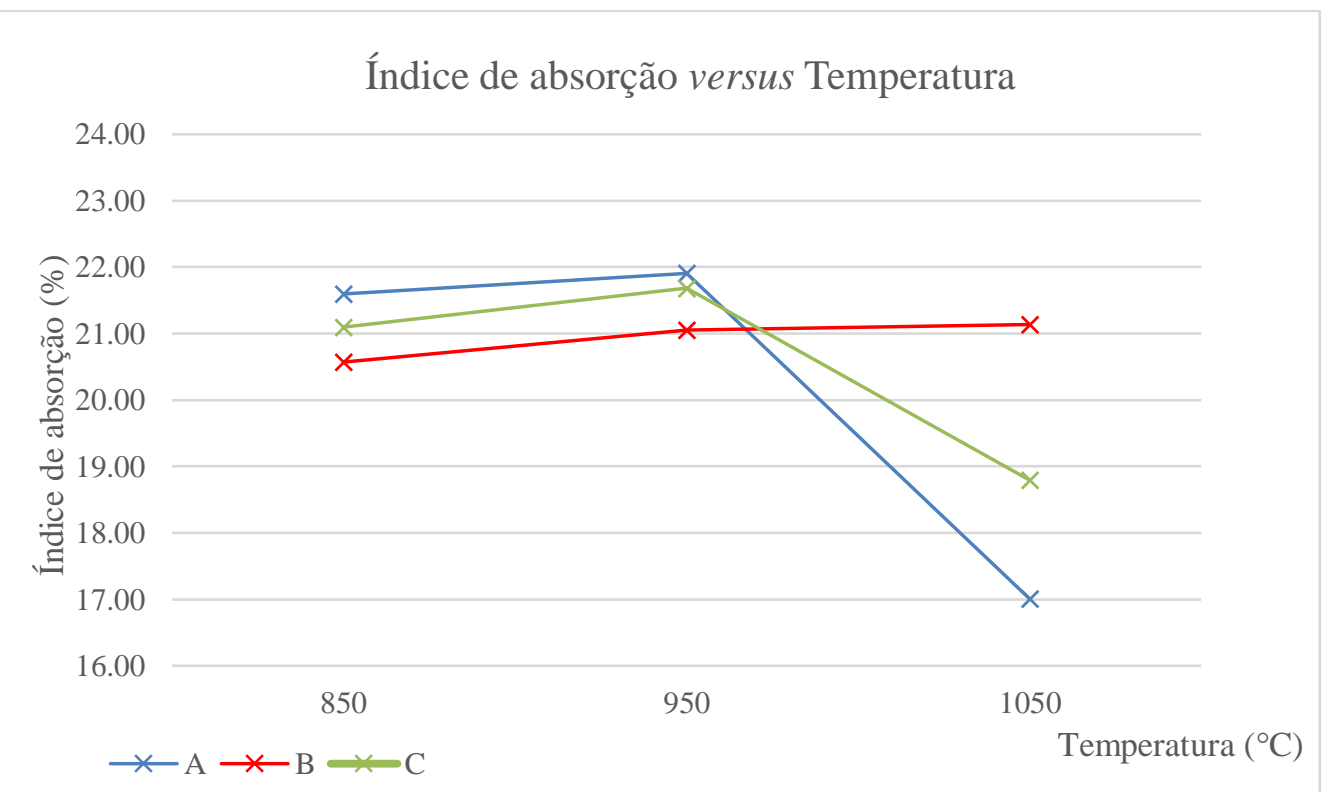

Figura 9. Curvas de Índice de absorção versus temperatura para as três misturas propostas: A, B e C. 
As misturas A e C apresentaram menores índices de absorção a $1050^{\circ} \mathrm{C}$. Esse comportamento já era esperado, pelo fato de que a partir de $1050^{\circ} \mathrm{C}$ ocorre o preenchimento dos poros devido à reorganização dos argilominerais em novas estruturas cristalinas, levando a uma queda da absorção. A $850^{\circ} \mathrm{C}$ e $950^{\circ} \mathrm{C}$ observou-se menores valores de absorção nas misturas com adição de chamote.

A mistura $\mathrm{B}$, que contém a maior proporção de resíduo em sua composição, apresentou menor índice de absorção a $850^{\circ} \mathrm{C}$, e menores valores em relação às outras duas misturas a $850^{\circ} \mathrm{C}$ e $950^{\circ} \mathrm{C}$. Ressalta-se que as três misturas apresentaram valores de absorção dentro do limite máximo de $22 \%$ estipulado pela ABNT NBR 15270 [16].

$\mathrm{Na}$ Figura 10 são mostradas as curvas relacionadas à resistência à flexão dos corpos de prova testados.

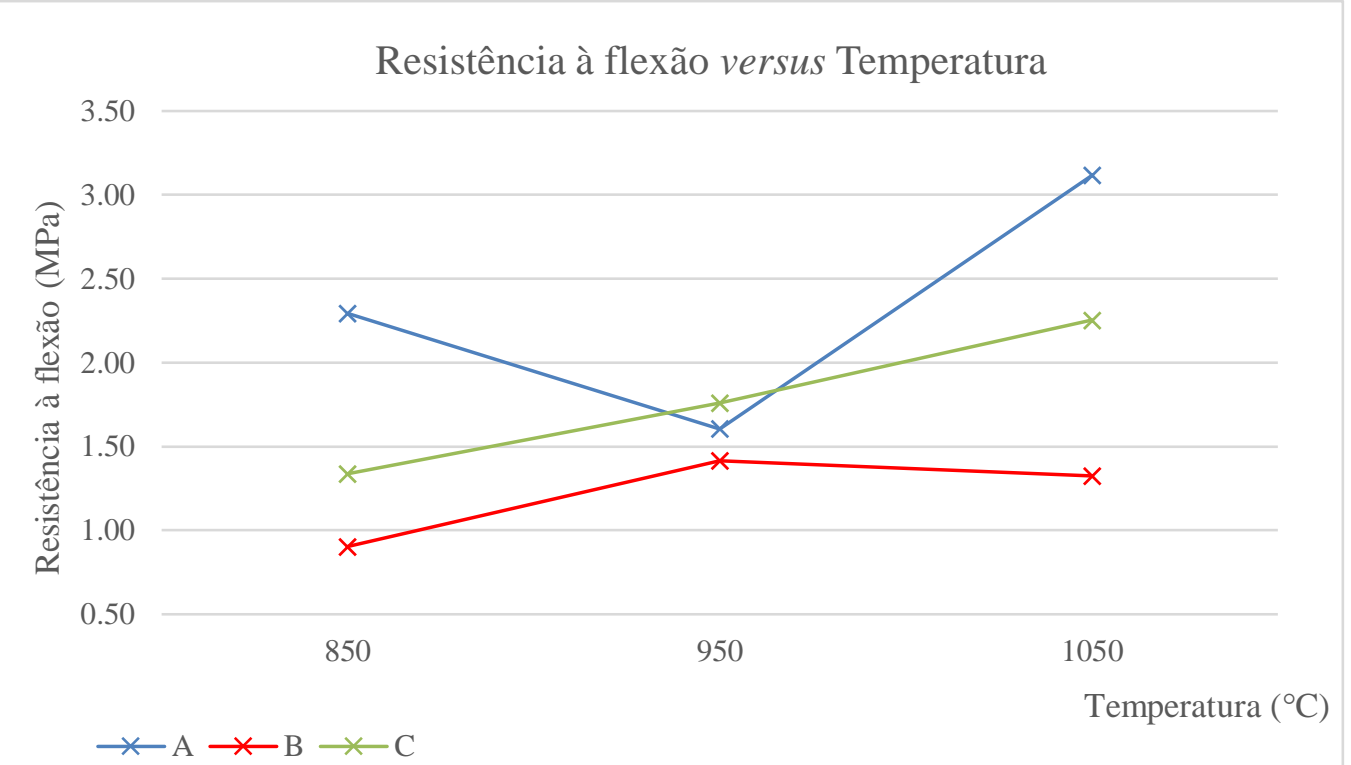

Figura 10. Curvas de Resistência à flexão versus temperatura para as três misturas propostas: A, B e C.

Considerando-se as curvas de variação da resistência à flexão em função da temperatura de queima, observa-se um aumento da resistência com o aumento da temperatura nas misturas B e C, comportamento também verificado por Gouveia e Sposto [7]. A mistura A apresentou uma queda de resistência a $950^{\circ} \mathrm{C}$, seguida de um aumento de aproximadamente $100 \%$. Essa queda provavelmente ocorreu devido a algum erro de execução do ensaio ou quando da coleta dos dados.

A mistura $\mathrm{C}$, cuja composição contem maior porcentagem de resíduo, apresentou os melhores valores a $950^{\circ} \mathrm{C}$. Observa-se a tendência de diminuição da resistência à flexão com o aumento na temperatura a $850^{\circ} \mathrm{C}, 950^{\circ} \mathrm{C}$ e $1050^{\circ} \mathrm{C}$. De fato, assim como o concluído por Vieira, Teixeira e Monteiro [1] e Gouveia e Sposto [7], a resistência mecânica reduz com crescentes adições de chamote. Isto pode ser explicado pela pouca adesão das partículas inertes do resíduo à matriz das massas cerâmicas, tornando-se pontos de concentração de tensões. Ressalta-se que 0 efeito negativo sobre a resistência mecânica ainda foi significativo mesmo submetendo o resíduo a temperaturas maiores em relação a de primeira queima. 


\section{CONCLUSÃO}

A adição de chamote, nas três temperaturas avaliadas, contribui para a redução da retração linear na queima, o que pode ser considerado benéfico na produção de blocos cerâmicos, devido à diminuição das trincas por retração.

Os valores de absorção de água sofreram aumento gradativo, até a temperatura de $950^{\circ} \mathrm{C}$, em todas as misturas avaliadas. A $1050^{\circ} \mathrm{C}$ ocorreu uma quebra brusca nos valores das misturas $A$ e $C$, devido ao processo de vitrificação. Já a mistura $B$ apresentou um pequeno aumento a esta temperatura, concluindo-se que a maior quantidade de chamote possa ter interferido no processo supracitado.

Quanto à resistência à flexão, maiores adições de resíduo influenciam negativamente na resistência independentemente da temperatura avaliada. Observou-se que a tensão de ruptura à flexão aumentou em razão do aumento de temperatura, sendo os valores máximos a $1050^{\circ} \mathrm{C}$.

Dentre as duas composições com chamote avaliadas, conclui-se que a mistura com $13,33 \%$ de resíduo apresentou melhor comportamento quanto à absorção e resistência mecânica, sobretudo quando submetida à temperatura de $1050^{\circ} \mathrm{C}$. No entanto, para a escolha da quantidade ideal de resíduo a ser incorporada à massa cerâmica no processo de produção, faz-se necessário o estudo de outras composições, abrangendo teores de chamote intermediários.

A utilização do resíduo de blocos cerâmicos na própria massa cerâmica mostra-se viável e configura-se como uma alternativa válida para ser aplicada dentro das indústrias. Esta prática acarreta vantagens econômicas, ambientais e, consequentemente, sociais, já que possibilita também a redução no preço final do produto.

\section{Agradecimentos}

Os autores agradecem à CAPES e ao Laboratório de Engenharia Civil da Universidade Federal de Viçosa pelo suporte dado ao desenvolvimento da pesquisa.

\section{REFERÊNCIAS}

1 Vieira CMF, Teixeira SS, Monteiro SN. Efeito da temperatura de queima nas propriedades e microestrutura de cerâmica vermelha contendo chamote. Cerâmica. 2009;55:332-336.

2 Sales ATC, Alferes Filho RS. Efeito do pó de resíduo cerâmico como adição ativa para o concreto. Ambiente construído. 2014;14(1):113-125.

3 Gomes PG, Cardoso IC, Souza MS, Brochado MR. Análise da absorção de resíduos industriais por cerâmicas vermelhas. In: Universidade Federal Fluminense. Anais do $10^{\circ}$ Congresso Nacional de Excelência em Gestão; 2014; Rio de Janeiro, Brasil. Rio de Janeiro: UFF; 2014. p. 1-15.

4 Paixão SO. Estudo do uso de resíduo cerâmico de obras como agregado miúdo para a fabricação de argamassas para revestimento de alvenarias [projeto de graduação]. Rio de Janeiro: Universidade Federal do Rio de Janeiro; 2013.

5 Amorim LV, Pereira ASG, Neves GA, Ferreira HC. Reciclagem de rejeitos de cerâmica vermelha e da construção civil para a obtenção de aglomerantes alternativos. Cerâmica Industrial. 2000;5(4):35-46.

6 Zaccaron A, Galatto SL, Nandi VS, Fernandes P. Incorporação de chamote na massa de cerâmica vermelha como valorização do resíduo. Cerâmica Industrial.

2014;19(3):33-39. 
7 Gouveia FP, Sposto RM. Incorporação de chamote em massa cerâmica para a produção de blocos. Um estudo das propriedades físico-mecânicas. Cerâmica. 2009;55:415-419.

8 Pracidelli S, Melchiades FG. Importância da composição granulométrica de massas para a cerâmica vermelha. Cerâmica Industrial. 1997;2(1/2):31-35.

9 Campelo NS, Morais MR, Aragão AF, Cabral EM, Rebelo EP, Pinheiro SC, et al. Cerâmica Industrial. 2006;11(1):44-46.

10 Associação Brasileira de Normas Técnicas. NBR 7181: Solo - Análise granulométrica. Rio de Janeiro: ABNT; 1984.

11 Associação Brasileira de Normas Técnicas. NBR 6508: Grãos de solo que passam na peneira de 4,8 mm - Determinação da massa específica. Rio de Janeiro: ABNT; 1984.

12 Associação Brasileira de Normas Técnicas. NBR 6459: Determinação do limite de liquidez: método de ensaio. Rio de Janeiro: ABNT; 1984.

13 Caputo HP. Mecânica dos solos e suas aplicações. Rio de Janeiro: LTC; 1981.

14 Barba et al. Materias primas para la fabricación de soportes de baldosas cerâmicas. Castellón: Instituto de Tecnología Cerámica; 1997.

15 Emiliani GP, Corbara F. Tecnologia cerâmica. Faenza: Editoriale Faenza Editrice; 1999.

16 Associação Brasileira de Normas Técnicas. NBR 15270: Componentes cerâmicos. Rio de Janeiro: ABNT; 2005. 